Article

\title{
Genetic Structure and Eco-Geographical Differentiation of Wild Sheep Fescue (Festuca ovina L.) in Xinjiang, Northwest China
}

\author{
Chenglin Zhang ${ }^{1}{ }^{\mathbb{D}}$, Jianbo Zhang ${ }^{2}$, Yan Fan ${ }^{3}$, Ming Sun ${ }^{1}$, Wendan $\mathrm{Wu}^{1}$, Wenda Zhao ${ }^{1}$, \\ Xiaopeng Yang ${ }^{1}$, Linkai Huang ${ }^{1}{ }^{(\mathbb{D})}$, Yan Peng ${ }^{1}$, Xiao $\mathrm{Ma}^{1, *}$ and Xinquan Zhang ${ }^{1, *}$ \\ 1 Department of Grassland Science, Animal Science and Technology College, Sichuan Agricultural University, \\ Chengdu 611130, China; zcl0636@126.com (C.Z.); sunming4709@163.com (M.S.); \\ wuwendandan@163.com (W.W.); zwd89897@163.com (W.Z.); 18227587409@163.com (X.Y.); \\ huanglinkai@sicau.edu.cn (L.H.); pengyanlee@163.com (Y.P.) \\ 2 Sichuan Academy of Grassland Science, Chengdu 610097,China; zhangjianber@163.com \\ 3 Chongqing Academy of Animal Husbandry, Chognqing 400039, China; cq_fy001@163.com \\ * Correspondence: maroar@126.com (X.M.); zhangxq@sicau.edu.cn (X.Z.); Tel.: +86-138-8244-9603 (X.M.)
}

Received: 18 July 2017; Accepted: 4 August 2017; Published: 9 August 2017

\begin{abstract}
Glaciation and mountain orogeny have generated new ecologic opportunities for plants, favoring an increase in the speciation rate. Moreover, they also act as corridors or barriers for plant lineages and populations. High genetic diversity ensures that species are able to survive and adapt. Gene flow is one of the most important determinants of the genetic diversity and structure of out-crossed species, and it is easily affected by biotic and abiotic factors. The aim of this study was to characterize the genetic diversity and structure of an alpine species, Festuca ovina L., in Xinjiang, China. A total of 100 individuals from 10 populations were analyzed using six amplified fragment length polymorphism (AFLP) primer pairs. A total of 583 clear bands were generated, of which 392 were polymorphic; thus, the percentage of polymorphic bands (PPB) was $67.24 \%$. The total and average genetic diversities were 0.2722 and $0.2006(0.1686-0.2225)$, respectively. The unweighted group method with arithmetic mean (UPGMA) tree, principal coordinates analysis (PCoA) and Structure analyses revealed that these populations or individuals could be clustered into two groups. The analysis of molecular variance analysis (AMOVA) suggested that most of the genetic variance existed within a population, and the genetic differentiation (Fst) among populations was $20.71 \%$. The Shannon differentiation coefficient (G'st) among populations was 0.2350. Limited gene flow $(\mathrm{Nm}=0.9571)$ was detected across all sampling sites. The Fst and Nm presented at different levels under the genetic barriers due to fragmentation. The population genetic diversity was significant relative to environmental factors such as temperature, altitude and precipitation.
\end{abstract}

Keywords: Festuca ovina L.; AFLP; genetic diversity; genetic barriers; environmental factors

\section{Introduction}

Glaciation and mountain orogeny are the main factors that shape landscapes and change climate, and they have been linked to recent diversification and speciation events $[1,2]$. They could create many different environments and microclimates, which provide new habitats for plants and trigger evolutionary processes [3]. Accumulating evidence suggests that historical glacial and orogenic movements, including some recent biotic activities, might cause habitat fragmentation, which seriously increases the vulnerability of many plant species and threatens their survival [4]. These factors could also alter the abundance and behavior of pollinators and restrict seed dispersal $[5,6]$. The primary changes during habitat fragmentation include reduced population sizes and increased spatial isolation 
among populations [7]. Consequently, a deleterious erosion of genetic diversity and intensification of inter-population divergence would occur by random genetic drift, elevated inbreeding, and decreased inter-population gene flow [8,9]. As the feedback, fitness, richness and adaptation ability of a population would be weakened, such changes could even cause the local extinction of demes within a meta-population $[10,11]$.

High genetic diversity is fundamental for the ability of a species to survive and develop [12]. It is often associated with traits that enable a species to adapt, such as expanding their distribution range and creating a new niche $[13,14]$. Fragmentation can affect plant species differently depending on their life history traits. The genetic erosion derived from habitat fragmentation depends on multiple life traits, including population size, distance between populations, time since isolation, seed and pollen dispersal distance, and generation time [15]. For out-crossed species, gene flow via pollen and seed dispersal is one of the most important determinants in the establishment of population genetic diversity and structure [16]. However, gene flow is often interrupted by isolation and environmental heterogeneity [17-19]. Notably, historical climatic oscillations have greatly influenced the biodiversity of plant species. These effects were normally manifested by population contractions and expansions, long-distance range dispersal, new habitat colonization and in situ survival in glacial refugia [20,21]. Consequently, genetic erosion has occurred in some species. Researching the contemporary genetic diversity of species is required to understand ecological adaption processes and historical evolution. Hence, rational utilization and conservation practices are more effectively and efficiently realized for plant germplasms with agricultural importance.

The genus Festuca (Poaceae), with its approximately 100 species, is one of the most prevalently used grass genera, presenting a wide cosmopolitan distribution in the world [22]. Among these species, Festuca ovina L. is a perennial, cool-season and outbreeding grass aggregate with considerable agricultural and ecological importance $[23,24]$. Its main ploidy levels are documented: diploid $2 n=4 x=14$ and tetraploid $2 n=4 x=28$ [25]. Due to its strong tolerance to stress and adversity, Festuca ovina L. survives well in various habitats, which range from acid soils, coastal dunes and cliffs to cold deserts and heavy metal soils. Moreover, this species is abundant in Eurasia, ranges from the Arctic to the warm temperate zone, and is even found in outlying areas further south [25,26]. Festuca ovina L. is often used as a constructive species, turf grass, hay or grazing grass due to its multi-tillers and nutritional value (i.e., sugar and protein content), and it also presents considerable ecological resistance to sandstorms and soil erosion in some alpine and desert areas [23,26]. Generally, F. ovina and Stipa purpurea are the dominate species of Temperate steppe in Xinjiang, China, while a large number of Leymus, Potentilla and deleterious Leguminosae plants have invaded, expanded and occupied the dominant position in degraded ecosystem because of global climate changes, overexploitation, overgrazing and pollution $[27,28]$. The stability and quantitative characteristics of the F. ovina community indicate high volatility and vulnerability and the population size is gradually decreasing, causing genetic erosion that seriously impedes the sustainable development of the region's ecological security and local animal husbandry.

The Tianshan Mountains in Xinjiang of China and Central Asia are three parallel fold mountains that present a typical case of glaciation and orogenic movement $[29,30]$. They have contributed an important influence on plant biodiversity since their uplift during the early Holocene because they have acted as an East-West corridor, allowing lineage exchange, but also as a North-South barrier, promoting vicariance [31]. Moreover, desert expansion, environmental aridification, and river course dynamics have significant roles in providing adequate habitats for persistence of many plant species that could tolerate extreme drought and cold through glacial cycles [32,33]. Investigations of the genetic diversity of many species have been carried out in Xinjiang, but rarely for F. ovina. Actually, the heterogeneity of landscapes triggered by orogenic movements has formed many special habitats [34,35]. Many alleles and traits related to adaptation have been filtered under these special eco-geographic habitats due to their independent development at different elevations or under different edaphic characteristics, temperatures or levels of precipitation $[18,36]$. The morphological assessment and isozyme methods 
need a long time and considerable effort to establish the individuals and populations in replicated field experiments in homogenous environments, while the molecular marker techniques such as amplified fragment-length polymorphism (AFLP) analysis are more efficient because they provide much more detailed insight into genetic diversity and variation at the DNA level [37,38]. It is possible to evaluate a large number of polymorphic loci for any origin or level of DNA complexity without prior genomic information. Thus, AFLP has been widely used to determine phylogenetic history, answer important ecological questions and assess germplasm resources [39,40].

In this study, AFLP was used to investigate the genetic diversity and structural patterns of 100 wild F. ovina individuals from 10 populations found in Xinjiang. The aims were to (1) characterize the level of genetic diversity and the distribution of genetic variation within and among $F$. ovina populations; (2) calculate the gene flow and differentiation among populations at different scale and fragmented patterns; and (3) discuss the influence of environmental factors on population genetic diversity and structure. As a consequence, this study supplies a basis for the collection and protection of germplasm resources.

\section{Results}

\subsection{AFLP Polymorphism and Genetic Diversity}

In this study, the six selected AFLP primer pairs generated 583 clear bands that corresponded to an average of 97.17 per primer pair (Table 1). Among these bands, 392 were polymorphic. As the polymorphic bands for each primer ranged from 56 to 70, the percentage of polymorphic bands (PPB) was $67.24 \%$. The polymorphism information content (PIC) varied from 0.1917 (E85M57) to 0.2221 (E42M85), with an average of 0.2107 . The total Nei's genetic diversity $(\mathrm{Hj})$ of the primer pairs was $0.3549(0.2036-0.3024)$, which corresponded to an average of 0.2531 . The Shannon diversity index (Ho) of primer pairs varied from 0.20462 to 0.4406 , and the total and average Ho values were 0.4642 and 0.3164 , respectively.

Table 1. Summary of genetic diversity based on AFLP loci amplified by each primer combination. Total number of bands (TNB), number of polymorphic bands (NPB), percentage of polymorphic bands (PPB), polymorphism information content (PIC), Nei's genetic diversity $(\mathrm{Hj})$, Shannon diversity index (Ho).

\begin{tabular}{ccccccc}
\hline Primer & TNB & NPB & PPB (\%) & PIC & Hj & Ho \\
\hline E42M57 & 109 & 70 & 64.22 & 0.2132 & 0.2538 & 0.2136 \\
E42M85 & 89 & 56 & 62.92 & 0.2221 & 0.3024 & 0.3617 \\
E85M57 & 101 & 66 & 65.35 & 0.1917 & 0.2628 & 0.4406 \\
E85M85 & 103 & 68 & 66.02 & 0.2152 & 0.2464 & 0.2261 \\
E86M57 & 90 & 67 & 74.44 & 0.2095 & 0.2036 & 0.2046 \\
E86M85 & 91 & 65 & 71.43 & 0.2124 & 0.2499 & 0.4116 \\
Total & 583 & 392 & 67.24 & 0.2107 & 0.3549 & 0.4642 \\
Mean & 97.17 & 65.33 & 67.24 & 0.2107 & 0.2531 & 0.3164 \\
\hline
\end{tabular}

The genetic diversities of 10 F. ovina populations are listed in Table 2. The number of polymorphic loci (Np) ranged from 198 (FO-04) to 294 (FO-06), and the total and average Np were 392 and 298.5, respectively. The average percentage of polymorphic loci (PPL) was $67.24 \%(50.5 \%-75.0 \%)$. The total $\mathrm{Hj}$ and total Shannon diversity index (Ho) were 0.2622 and 0.2988 , respectively; these values were highest in FO-07 $(\mathrm{Hj}=0.2225, \mathrm{Ho}=0.2505)$ and lowest in FO-04 $(\mathrm{Hj}=0.1686, \mathrm{Ho}=0.1966)$. The average observed number of alleles per locus (Na) was 1.6314 (1.5026-1.7092), and the average effective number of alleles per locus $(\mathrm{Ne})$ was $1.3043(1.2585-1.3425)$. 
Table 2. Genetic variability in 10 Festuca ovina populations. Number of polymorphic loci (Np), percentage of polymorphic loci (PPL), observed number of alleles per locus (Na), effective number of alleles per locus $(\mathrm{Ne})$, Nei's gene diversity index $(\mathrm{Hj})$, Shannon diversity index $(\mathrm{Ho})$.

\begin{tabular}{ccccccc}
\hline Population & Np & PPL (\%) & Na & Ne & Hj & Ho \\
\hline FO-01 & 272 & 69.4 & 1.6582 & 1.2982 & 0.2042 & 0.2343 \\
FO-02 & 271 & 69.1 & 1.6709 & 1.3401 & 0.2191 & 0.2469 \\
FO-03 & 282 & 71.9 & 1.6607 & 1.2920 & 0.1969 & 0.2214 \\
FO-04 & 198 & 50.5 & 1.4719 & 1.2625 & 0.1686 & 0.1966 \\
FO-05 & 274 & 69.9 & 1.6786 & 1.3227 & 0.2126 & 0.2461 \\
FO-06 & 294 & 75.0 & 1.7092 & 1.3006 & 0.2054 & 0.2327 \\
FO-07 & 271 & 69.1 & 1.6735 & 1.3425 & 0.2225 & 0.2505 \\
FO-08 & 256 & 65.3 & 1.6352 & 1.3140 & 0.2068 & 0.2336 \\
FO-09 & 202 & 51.5 & 1.5026 & 1.2585 & 0.1698 & 0.1982 \\
FO-10 & 273 & 69.6 & 1.6531 & 1.3119 & 0.1998 & 0.2264 \\
Total & 392 & 100 & 2.0000 & 1.3571 & 0.2622 & 0.2988 \\
Mean & 298.5 & 67.24 & 1.6314 & 1.3043 & 0.2006 & 0.2287 \\
\hline
\end{tabular}

\subsection{Genetic Distance and Structure}

A total of 392 fragments from six AFLP loci were used to estimate pairwise Nei's genetic distances (GD) among 10 F. ovina populations (Table 3). The genetic distance was relatively low, varying from 0.0802 (FO-03 vs. FO-04) to 0.1508 (FO-05 vs. FO-09) with an average value of 0.1094. Lower genetic distances indicated a closer relationship among the studied populations, although some visible differences obviously exist between them.

Table 3. Nei's genetic distance matrix of $10 \mathrm{~F}$. ovina populations based on AFLP (amplified fragment-length polymorphism) profiles. Genetic distance (GD).

\begin{tabular}{cccccccccc}
\hline GD & FO-02 & FO-03 & FO-04 & FO-05 & FO-06 & FO-07 & FO-08 & FO-09 & FO-10 \\
\hline FO-01 & 0.0823 & & & & & & & & \\
FO-02 & 0.0853 & 0.0804 & & & & & & & \\
FO-03 & 0.1504 & 0.1418 & 0.1504 & & & & & & \\
FO-04 & 0.0866 & 0.0802 & 0.0890 & 0.1432 & & & & & \\
FO-05 & 0.088 & 0.0833 & 0.0811 & 0.1477 & 0.0814 & & & & \\
FO-06 & 0.0867 & 0.0869 & 0.0921 & 0.1486 & 0.0919 & 0.0942 & & & \\
FO-07 & 0.0934 & 0.0957 & 0.0978 & 0.1473 & 0.0952 & 0.0999 & 0.0889 & & \\
FO-08 & 0.1486 & 0.1393 & 0.1499 & 0.0911 & 0.1441 & 0.1462 & 0.1483 & 0.1495 & \\
FO-09 & 0.0897 & 0.0829 & 0.0836 & 0.1508 & 0.0824 & 0.0839 & 0.0962 & 0.0986 & 0.1498 \\
\hline
\end{tabular}

To study the genetic structure of $F$. ovina, a UPGMA (unweighted pair-group method with arithmetic means) clustering analysis at the species level was conducted (Figure 1a). The results showed that the 10 populations gathered into two clusters with a bootstrapping value of $100 \%$. Cluster I contained 8 populations (FO-01, FO-02, FO-03, FO-05, FO-06, FO-07, FO-08 and FO-10), whereas Cluster II contained 2 populations (FO-04 and FO-09). We performed a Structure analysis to further study the genetic structure (Figure $1 \mathrm{~b}, \mathrm{c}$ ). This analysis revealed that the 10 populations clustered into two groups, FO-04 and FO-09 clustered into the same group, and the remaining 8 populations were clustered into an alternative group. This result was highly consistent with that of the UPGMA tree.

Principal coordinates analysis (PCoA) was performed on the entire dataset of 100 individuals. The results showed that these individuals were divided into two groups (Figure 2). The individuals of FO-01, FO-02, FO-03, FO-05, FO-06, FO-07, FO-08 and FO-10 were gathered into Group I, whereas the individuals of FO-04 and FO-09 were gathered into Group II. The first principal vector explained $16.07 \%$ of the genetic variation, whereas the second and third principal vectors explained $4.50 \%$ and $3.86 \%$ of the genetic variation, respectively. This result was also consistent with those of the UPGMA tree and STRUCTURE analysis. 
a

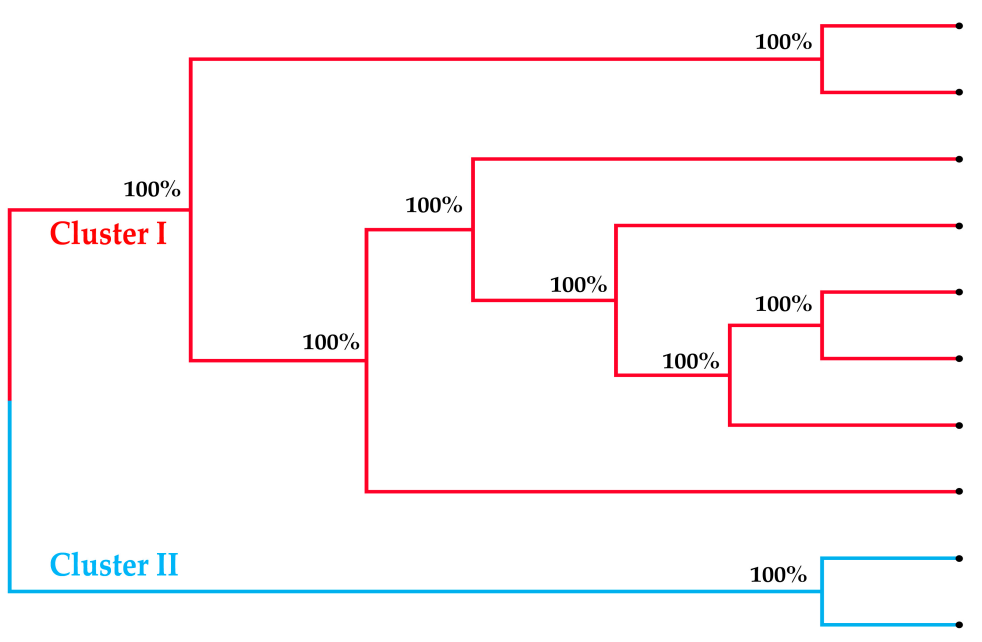

0.8 b

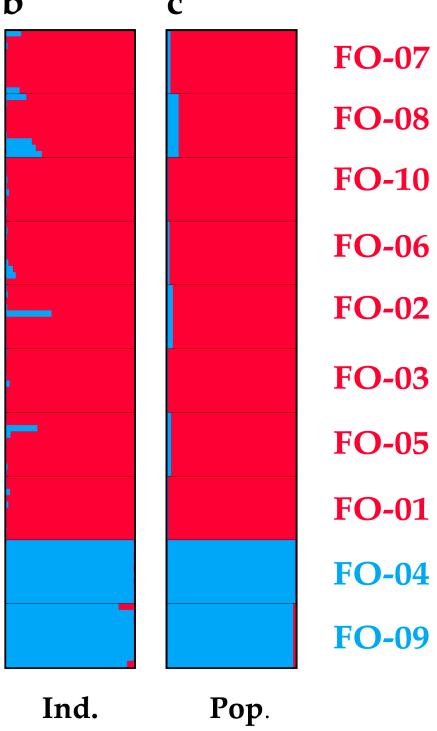

Figure 1. Cluster analysis for F. ovina ((a) UPGMA (unweighted pair-group method with arithmetic means) tree for 10 populations, (b) structure analysis for 100 individuals, (c) structure analysis for 10 populations). Two colors represented different potential genetic backgrounds.

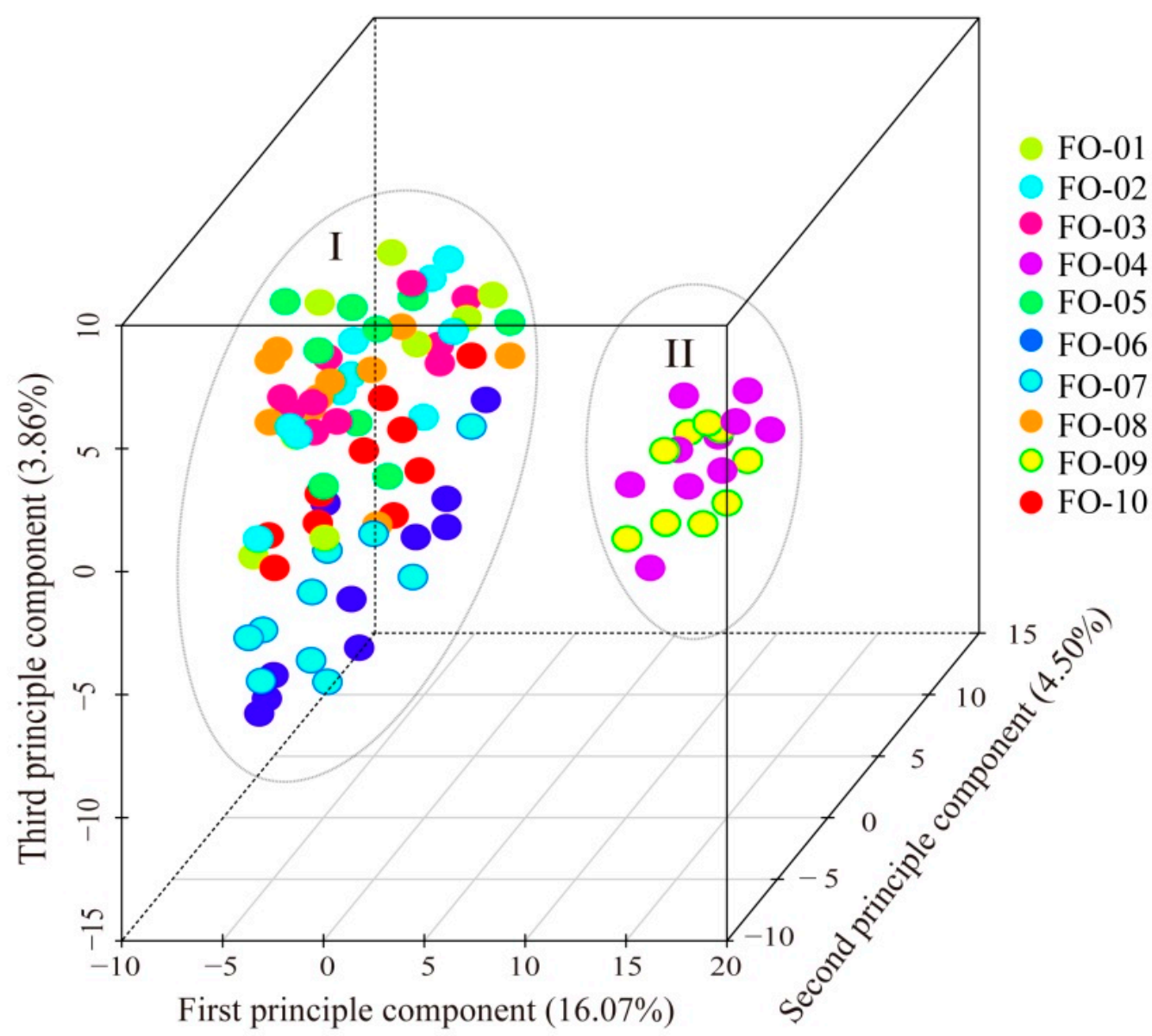

Figure 2. Principal coordinates analysis (PCoA) of 100 F. ovina individuals from 10 populations based on genetic distance matrix. The 10 individuals of per population were represented by the same dots. 


\subsection{Genetic Differentiation, Gene Flow and Genetic Barrier}

Analysis of molecular variance (AMOVA) was conducted to further evaluate the partitioning of genetic differentiation among and within F. ovina populations (Table 4). The results showed that $20.71 \%$ of the genetic differentiation occurred among populations, whereas $77.83 \%$ was attributable to variability within populations. Furthermore, AMOVA was conducted for the two clusters determined by the UPGMA tree and STRUCTURE analysis. The results suggested that $11.54 \%$ of the genetic differentiation occurred between the two clusters. Moreover, the Shannon differentiation coefficient was also calculated as $\mathrm{G}^{\prime} \mathrm{st}=0.2350$ among all populations. The gene flow was $\mathrm{Nm}=0.9571$ across all sampling sites.

Table 4. Analysis of molecular variance for F. ovina populations.

\begin{tabular}{cccccccc}
\hline Group & Source of Variation & D.f. & $\begin{array}{c}\text { Sum of } \\
\text { Squares }\end{array}$ & $\begin{array}{c}\text { Variance } \\
\text { Components }\end{array}$ & $\begin{array}{c}\text { Percentage } \\
\text { of Variation }\end{array}$ & F-Statistic & $p$-Value \\
\hline Two clusters & Among clusters & 2 & 2334.77 & 11.98 & 11.54 & Fct $=0.1154$ & $<0.01$ \\
& Among pops. within clusters & 7 & 2143.16 & 9.74 & 10.54 & Fsc $=0.1054$ & $<0.01$ \\
& Within populations & 89 & 4477.93 & 46.53 & 77.92 & Fst $=0.2208$ & $<0.01$ \\
& Total & 98 & 5647.54 & 58.68 & & & \\
\hline \multirow{2}{*}{ All pops. } & Among populations & 9 & 1169.60 & 12.15 & $20.71 \%$ & Fst $=0.2071$ & $<0.01$ \\
& Within populations & 89 & 4477.93 & 46.53 & $79.29 \%$ & & \\
\hline
\end{tabular}

Furthermore, a genetic barrier prediction analysis for 10 F. ovina populations was carried out using Monmonier's maximum difference algorithm. This analysis revealed three likely barriers against gene flow (Figure 3). The first barrier (aa) isolated FO-04 from its surrounding populations. The second barrier (bb) separated FO-09 from neighboring populations. The third barrier (cc) was detected between FO-07 and FO-01.

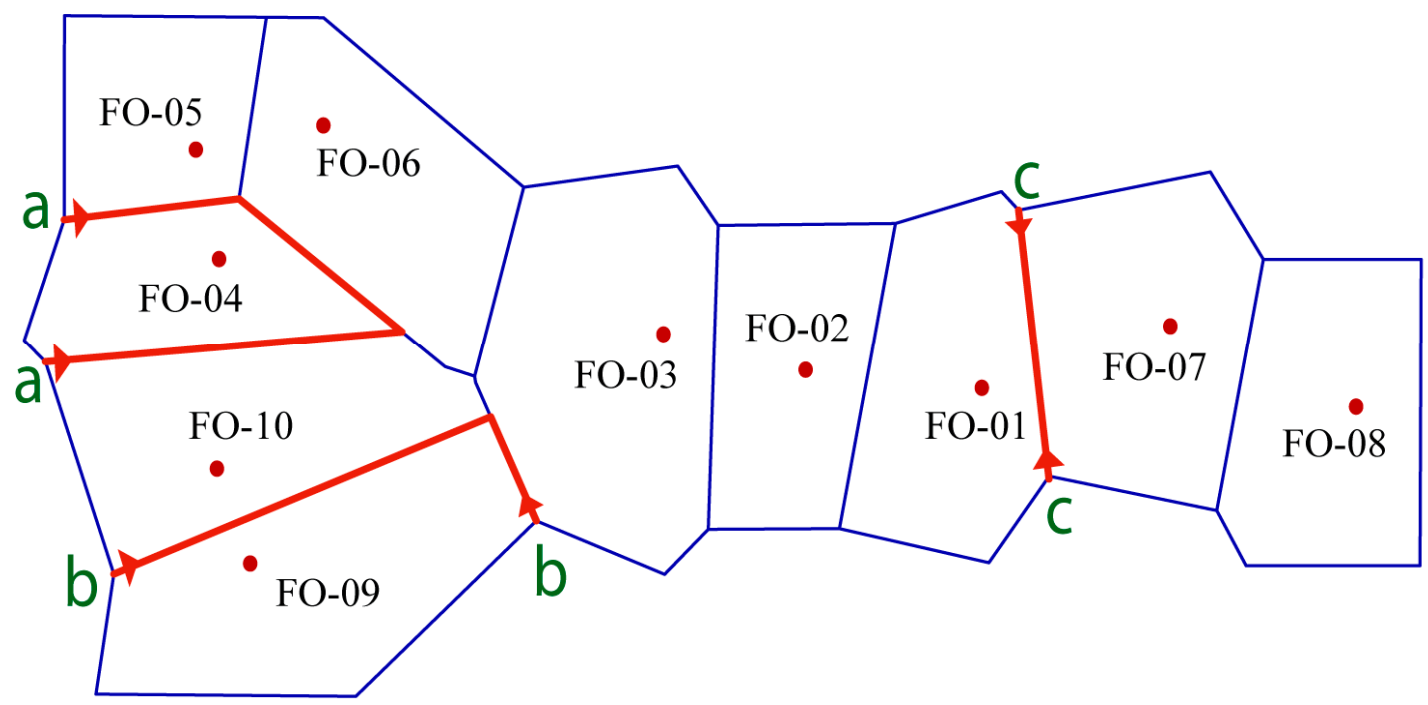

Figure 3. Genetic barriers predicted by BARRIER software (version 2.2, Syracuse University, New York, NY, USA). Lines a, b, and c indicated genetic barriers.

\subsection{Genetic Diversity Associated with Environmental Factors}

Pearson's correlation analyses showed that the Nei's genetic diversity $(\mathrm{Hj})$ of $F$. ovina populations significantly decreased with increasing geographic altitude $(r=-0.85, p<0.01)$ (Table 5; Figure 4a), indicating a pattern of lower genetic diversity at higher altitudes. The population $\mathrm{Hj}$ was weakly positively correlated to annual mean temperature $(r=0.5657, p<0.01)$ (Figure $4 \mathrm{~b}$ ), and weakly 
negatively related to annual precipitation $(r=-0.6007, p<0.01)$ (Figure $4 \mathrm{c}$ ). While population $\mathrm{Hj}$ was not related to longitude or latitude. The Shannon diversity index (Ho) also presented a similarly significant pattern $(r=-0.8368, p<0.01)$ to altitude, and weak correlation to annual precipitation $(r=-0.5715, p<0.01)$. No significant correlation was found between Ho and annual mean temperature, longitude or latitude. The percent of polymorphic loci (PPL) was also weakly correlated to altitude $(r=0.6077, p<0.01)$, and not related to annual mean temperature, annual precipitation, longitude or latitude.

Table 5. Pearson correlation analysis $(r)$ between genetic diversity and environmental factors.

\begin{tabular}{ccccccc}
\hline Variable & $\begin{array}{c}\text { Pearson } \\
\text { Coefficient }\end{array}$ & Altitude & $\begin{array}{c}\text { Annual Mean } \\
\text { Temperature }\end{array}$ & $\begin{array}{c}\text { Annual } \\
\text { Precipitation }\end{array}$ & Longitude & Latitude \\
\hline $\mathrm{Hj}$ & $r$ & -0.8500 & 0.5657 & -0.6007 & 0.5291 & 0.2953 \\
& $p$ & 0.0024 & 0.0096 & 0.0017 & 0.0024 & 0.0235 \\
\hline $\mathrm{Ho}$ & $r$ & -0.8368 & 0.5433 & -0.5715 & 0.5056 & 0.3288 \\
& $p$ & 0.0076 & 0.0120 & 0.0089 & 0.0032 & 0.0233 \\
\hline $\mathrm{PPL}$ & $r$ & -0.6077 & 0.2022 & -0.3919 & 0.2720 & 0.3975 \\
& $p$ & 0.0033 & 0.1310 & 0.0185 & 0.0118 & 0.0131 \\
\hline
\end{tabular}

a

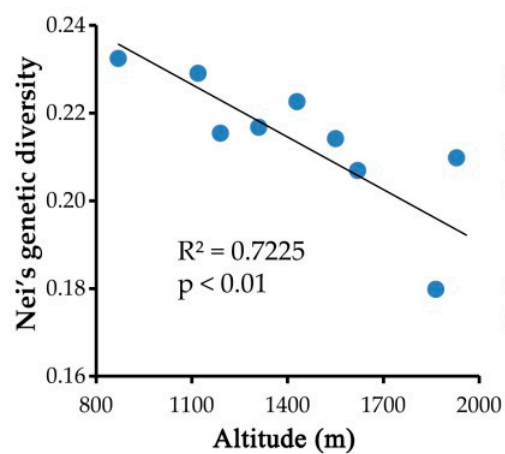

b

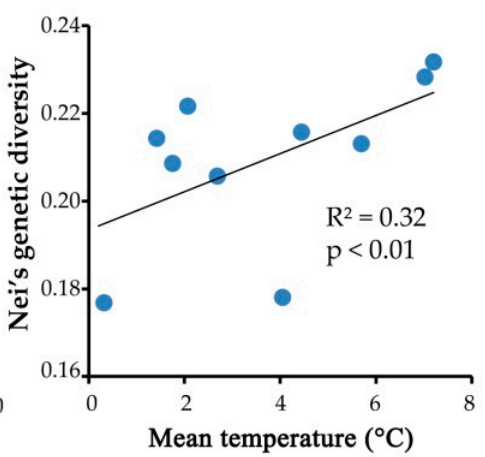

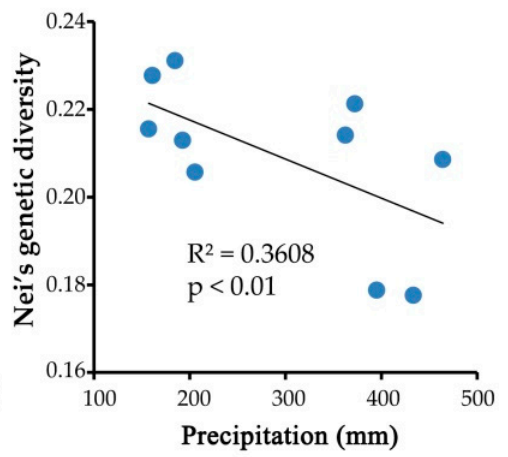

Figure 4. Regression analysis for $\mathrm{Hj}$ and environmental factors ((a) $\mathrm{Hj}$ and altitude; (b) $\mathrm{Hj}$ and mean temperature; (c) $\mathrm{Hj}$ and precipitation).

\section{Discussion}

\subsection{Population Genetic Diversity and Its Correlation to Environment Factors}

Genetic diversity is considered the consequence of long-term evolution and represents the evolutionary potential of a species to survive in various environments [13,41]. Thus, a species must accumulate more genetic diversity in order to adapt itself to diverse environmental pressures [42]. AFLP with high levels of polymorphism represents a powerful tool for assessing genetic diversity in many species $[37,43]$. In this study, a total of six AFLP primer pairs generated 583 clear bands, of which 392 were polymorphic; thus, the PPB was 65.33\%. The PIC ranged from 0.1917 to 0.2221 , with an average of 0.2107 . Previous research by Majidi et al. [44], in which the genetic variation of Fescue accessions was assessed using a DNA bulking strategy and AFLP, revealed an average NPB (number of polymorphic bands) of 41 and a PPB of 85.4\%. Higher PIC values, such as $0.2715(0.1534-0.3842)$ for genomic SSRs (simple sequence repeat) and 0.2224 (0.0760-0.4289) for EST-SSRs (expressed sequence tag-simple sequence repeat), than those of tall fescue were revealed by Tehrain et al. [45]. Generally, the population mean genetic diversity, genetic distance, and population size are positively correlated [46]. In most cases, widespread species tend to possess high genetic diversity. Conversely, the mean genetic distance (GD) in this study was $0.1094(0.0802-0.1508)$, which corresponded to 
an average genetic diversity of $\mathrm{Hj}=0.2006(0.1686-0.2225)$. Majidi et al. reported higher values of $\mathrm{GD}=0.55(0.12-0.81)$ and $\mathrm{Hj}=0.480(0.273-0.611)$ [44]. A molecular diversity analysis was conducted by Fjellheim et al. on Norwegian meadow fescue (Festuca pratensis Huds.) populations and Nordic cultivars, which revealed a lower genetic diversity $(\mathrm{Hj}=0.1412)$ [47]. Typically, cross-pollinated species maintain high intra-population variability relative to their inter-population variability [48]. The total genetic diversity $(\mathrm{Hj}=0.2822)$ and mean genetic diversity $(\mathrm{Hj}=0.2006)$ indicated the existence of $20.71 \%$ genetic differentiation among F. ovina populations, which corresponded well to the Shannon differentiation coefficient of $G^{\prime}$ st $=0.2512$. The study by Majidi et al. [44] revealed higher levels of $\mathrm{G}^{\prime}$ st $=0.337$ and Fst $=0.355$ among populations, whereas Fjellheim et al. [47] showed different differentiation patterns, such as Fst among seed populations (0.308), Fst among leaf populations (0.310) and Fst among cultivars (0.204). Currently, the high level of genetic diversity mirrors the high diversification and variation during long-term natural selection and evolutionary history, and genetic diversity benefits more easily from the broad geographical distribution range and high polyploidy for out-crossing species $[24,45]$. Conversely, the observations of this study suggested a relatively low genetic diversity of $F$. ovina populations. This low observed value of genetic diversity was possibly caused by different molecular markers or DNA strategies (individual DNAs or bulk DNAs). Alternatively, habitat fragmentation could be the explanation. Since the formerly panmictic population became fragmented, random genetic drift over time has led to both genetic differentiation among, and loss of heterozygosity within the fragmented population [49]. In the alpine area of Xinjiang, human overexploitation, overgrazing and farmland expansion have led to the increasingly patchy distribution and isolation of F. ovina, resulting in decreased fitness and reduced population size and thereby causing the observed low genetic diversity [27].

Evidence for lower genetic diversity at higher altitudes was found based on Pearson's correlation analysis between geographic altitude and Nei's genetic diversity $(r=-0.85, p<0.01)$ or Shannon diversity index $(r=-0.8368, p<0.01)$. For out-crossing species, wind, insects and animals are essential pollinators that guarantee gene flow within and among populations, these factors also determine the seed distribution of F. ovina [28]. Fewer insects and animals are found in alpine areas due to adverse environmental factors, including low temperatures, intense ultraviolet radiation and strong winds $[50,51]$. As a result, the plant population size gradually decreases, and deleterious erosion of genetic diversity occurs due to elevated levels of inbreeding and increased random genetic draft. Generally, ambient temperature could affect the growth and even alter the diversity of plants species, particularly in extremely low or high temperature. In this study, the Nei's genetic diversity was weakly positively correlated to annual mean temperature $(r=0.5657, p<0.01)$ (Figure $4 \mathrm{~b})$, and it partly revealed that low temperatures were harmful to plant genetic diversity when considering the glacial area. A previous study showed that glacial refugias in Tianshan Mountains and Altay area had an obvious effect on alpine plant species because migration and expansion normally occurred from these refugias [33]. Thus, the low observed value of genetic diversity of F. ovina in this study could be partly due to historic climate oscillation. For instance, suffering from the extremely low temperature, extinction occurred in mountain-top populations during glacial periods, whereas lowland populations survived due to the more tolerable temperatures [29,31]. Those alpine populations might have expanded from the few lowland individuals during the interglacial periods; therefore, less genetic diversity was observed. Furthermore, Nei's genetic diversity or Shannon diversity index $(r=0.5715$, $p<0.01)$ was weakly negatively correlated with annual precipitation $(r=-0.6007, p<0.01)$ (Figure 4c), partly indicating that excess rainfall was adverse for population genetic diversity. In Xinjiang, the wet season resulting from a temperate continental climate is concentrated in May and June every year [52,53]. So the continuous heavy rainstorms during the flowering period of F. ovina at May would disrupt the fertilization process and even reduce the population genetic diversity. Typically, the local microenvironment conditions would have great changes (such as temperature, intensity and duration of sunlight, climate, etc.) as the latitude and longitude increasing, which affect the distribution and development of plant species. Whereas the longitude and latitude didn't impact on 
genetic diversity of F. ovina populations in this study, these were probably limited by the scarcity of specimens, and further research with more sampling sites would confirm it.

\subsection{Genetic Structure and Gene Flow among Fragmented Populations under Genetic Barriers}

The population genetic structure can reveal the interactions of various evolutionary processes, such as habitat fragmentation, population isolation, and gene flow. In the present study, the UPGMA tree, PCoA and STRUCTURE analyses revealed that the 10 F. ovina populations comprised two clusters, and FO-04 and FO-09 were isolated from adjacent populations (Figures 1 and 2). Considering the relatively small distribution range of this species, the structural pattern of these populations was not related to their geographical distance, but instead, to their fragmentation. Most of the molecular variation was assigned to within-population variation ( $F s t=79.29 \%)($ Table 4$)$, which resulted from the high ploidy level and out-breeding of F. ovina. The possession of several copies of the genome and the outcrossing mating system of this species would favor the maintenance of high levels of both intra-individual and intra-population genetic diversity [24]. On the other hand, as discussed above, a relatively recent extinction and replacement could also explain the low genetic divergence among populations, leading to a lack of accumulated differential mutations over a relatively short evolutionary time [54].

Gene flow $(\mathrm{Nm})$ has an important impact on population genetic structure, evolutionary biology, conservation biology, and ecology [55]. High levels of gene flow can hinder intraspecific genetic drift and interspecific differentiation [56]. In this study, gene flow was $\mathrm{Nm}=0.9571$ among populations across all sampling sites, indicating the presence of some genetic barriers against gene flow. Three genetic barriers were directly detected and demonstrated in Figure 3. The first (aa) and second (bb) barriers isolated FO-04 and FO-09, respectively, from their adjacent populations. This result was congruent with the UPGMA tree, PCoA and STRUCTURE analyses. A further calculation was conducted for Fst and $\mathrm{Nm}$ at a smaller scale. The gene flow and genetic differentiation between FO-05, FO-06, FO-10 and FO-04 were $\mathrm{Nm}=1.1713$ and Fst $=0.1759$, respectively. The gene flow and genetic differentiation between FO-03, FO-10 and FO-09 were $\mathrm{Nm}=1.3282$ and Fst $=0.1584$, respectively. FO-04 and FO-09 were distributed in the alpine mountains with higher elevation, and thus, they had difficulty interacting with lowland populations. The explanation for this was the fragmentation induced by deserts and high mountains. Interestingly, FO-10 was distributed in the similar alpine area as FO-04 and FO-09, but low gene flow $(\mathrm{Nm}=1.2372)$ and high genetic differentiation ( $\mathrm{Fst}=0.1681)$ were found between these populations. An analogous differential pattern was also detected between FO-07 and FO-01 (Fst = 0.091) in lowland according to the third genetic barrier (cc). The reason for these might be the arid process and fragmentation due to desert expansion and high mountains that promoted the differentiation between adjacent populations [32,33]. Alternatively, FO-10 might be the colonization from lowland populations (as discussed above for historical climate oscillation), thereby explaining its similar genetic lineages and co-clustering in Cluster I (Figure 1).

\section{Materials and Methods}

\subsection{Plant Materials and Genomic DNA Preparation}

A total of 10 wild F. ovina populations (10 individuals per population) were sampled from Xinjiang, China in 2010 (Table 6). Individual spikes over $25 \mathrm{~m}$ apart from one another were sampled randomly to assure that they were from different individuals (Figure 5). A single seed from each collected single spike was germinated at Sichuan Agricultural University using an individual pot in an illumination incubator at an approximate temperature of $22{ }^{\circ} \mathrm{C}$ and under a $16 \mathrm{~h}$ photoperiod. Before DNA extraction, chromosome identification was carried out using the squashed root tips technique [57] for each individual 3-day-old germinated seedling to guarantee the DNA purity. The results suggested that all individuals and populations were diploid $(2 n=2 x=14)$. 
Table 6. List of the 10 wild F. ovina populations in this study.

\begin{tabular}{|c|c|c|c|c|c|c|c|}
\hline Population & $\begin{array}{c}\text { Altitude } \\
\text { (masl) }\end{array}$ & $\begin{array}{c}\text { Annual Mean } \\
\text { Temperature (AMT, }{ }^{\circ} \mathrm{C} \text { ) }\end{array}$ & $\begin{array}{c}\text { Annual Precipitation } \\
(\mathrm{AP}, \mathrm{mm})\end{array}$ & Longitude & Latitude & Grassland Type & Habitat and Dominant Herbs \\
\hline FO-01 & 1550 & 5.7125 & 207 & $86^{\circ} 22^{\prime} 0^{\prime \prime}$ & $43^{\circ} 53^{\prime} 1^{\prime \prime}$ & Temperate desert steppe & Ungrazed slope above road, with Leymus, Koeleria and Stipa \\
\hline FO-02 & 1120 & 7.0583 & 175 & $85^{\circ} 52^{\prime} 13^{\prime \prime}$ & $44^{\circ} 0^{\prime} 23^{\prime \prime}$ & Temperate desert steppe & Fenced pasture, with Artemisia and Seriphidium \\
\hline FO-03 & 1620 & 2.6625 & 220 & $84^{\circ} 38^{\prime} 5^{\prime \prime}$ & $44^{\circ} 9^{\prime} 12^{\prime \prime}$ & Temperate desert steppe & Natural pasture, with Stipa, Seriphidium, Aster and Festuca \\
\hline FO-04 & 2065 & 0.1375 & 451 & $81^{\circ} 8^{\prime} 24^{\prime \prime}$ & $44^{\circ} 31^{\prime} 0^{\prime \prime}$ & Temperate meadow steppe & Lakeside, with Stipa, Carex, Festuca, Taraxacum and Potentilla \\
\hline FO- 05 & 1430 & 2.0333 & 389 & $81^{\circ} 5^{\prime} 8^{\prime \prime}$ & $45^{\circ} 3^{\prime} 7^{\prime \prime}$ & Temperate steppe & Heavily grazed hill, with Artemisia, Potentilla and Seriphidium \\
\hline FO-06 & 1190 & 1.3750 & 379 & $81^{\circ} 33^{\prime} 9^{\prime \prime}$ & $45^{\circ} 10^{\prime} 0^{\prime \prime}$ & Temperate steppe & Heavily grazed hill, with Artemisia, Potentilla and Seriphidium \\
\hline FO- 07 & 870 & 7.2417 & 199 & $87^{\circ} 58^{\prime} 17^{\prime \prime}$ & $44^{\circ} 7^{\prime} 22^{\prime \prime}$ & Temperate desert steppe & Non-irriaged mountain pasture, with Stipa, Seriphidium and Aster \\
\hline FO-08 & 1310 & 4.4417 & 171 & $89^{\circ} 27^{\prime} 32^{\prime \prime}$ & $43^{\circ} 46^{\prime} 0^{\prime \prime}$ & Temperate desert steppe & Dry hills used for winter pastures, with Stipa, Seriphidium and Aster \\
\hline FO-09 & 1880 & 4.0458 & 412 & $81^{\circ} 18^{\prime} 23^{\prime \prime}$ & $43^{\circ} 1^{\prime} 42^{\prime \prime}$ & Temperate meadow steppe & Ungrazed hillside, with Stipa, Carex, Festuca and Taraxacum \\
\hline FO-10 & 1960 & 1.7125 & 482 & $81^{\circ} 7^{\prime} 24^{\prime \prime}$ & $43^{\circ} 29^{\prime} 26^{\prime \prime}$ & Temperate meadow steppe & Moderately grazed hillside, with Stipa, Carex, Taraxacum and Oxytropis \\
\hline
\end{tabular}


For each individual, genomic DNA was extracted from an aggregate of 3-5 fresh leaf tissues (approximately $80 \mathrm{mg}$ ) using a plant DNA extraction kit (Tiangen, Beijing, China) according to the manufacturer's instructions. The DNA concentration was quantified using a NanoDrop ${ }^{\circledR}$ ND-1000 Spectrophotometer (NanoDrop Technologies, Wilmington, DE, USA) and diluted to $100 \mathrm{ng} / \mu \mathrm{L}$ for AFLP analysis.

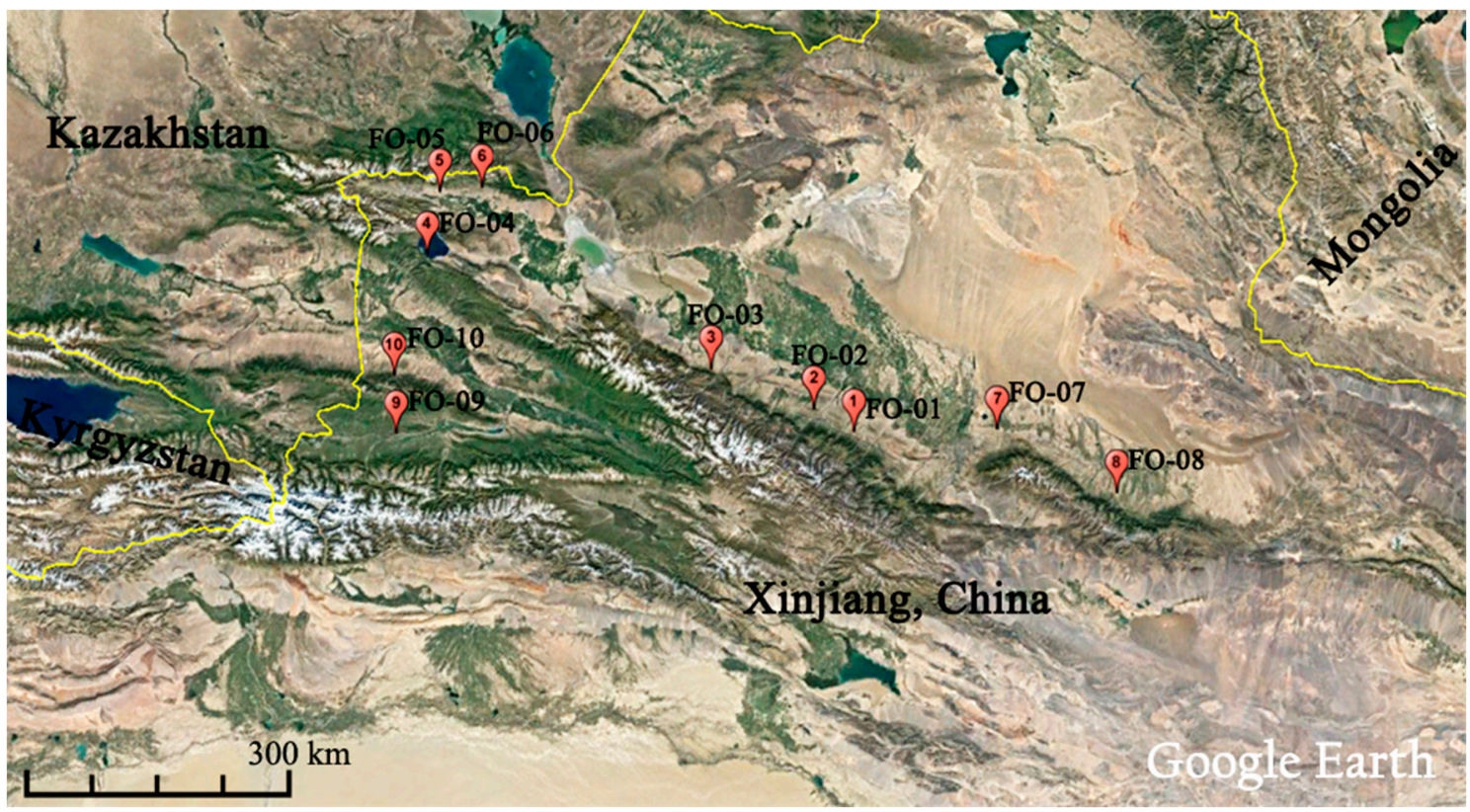

Figure 5. Geographical locations of analyzed populations of Festuca ovina in Xinjiang, China.

\subsection{AFLP Procedure}

The AFLP procedure was performed according to Sorkheh et al. [43]. A preliminary amplification using a set of 100 primer pairs identified six selective primer pairs as the most informative and reliable; these six primers were used for amplification. The PCR amplification reaction was performed in a $20 \mu \mathrm{L}$ system: 1 PCR buffer, $2 \mathrm{mM} \mathrm{MgCl}$, $2 \mathrm{mM}$ dNTP, $40 \mathrm{ng}$ of each of EcoRI primer and MseI primer, $1 \mathrm{U}$ Taq polymerase, and $5.0 \mu \mathrm{L}$ pre-amplified template DNA. The fragments amplified in the latter step were subjected to capillary electrophoresis using an ABI 3500 (Applied Biosystems, Foster City, CA, USA). GeneMarker (version 2.6, SOFTGENETICS, State College, PA, USA) was used to treat the fluorescent AFLP fragments for each individual sample.

\subsection{Data Analysis}

\subsubsection{Genetic Diversity}

Each band in the AFLP fingerprint pattern was considered a separate putative locus, and the bands clearly indicating AFLP amplification as 1 (presence) or 0 (absence) in a readable range (between 50 and $400 \mathrm{bp}$ ) were used to generated the binary matrices. The following parameters were calculated using EXCEL 2013 software (Microsoft, Redmond, WA, USA): total number of bands (TNB), number of polymorphic bands (NPB), percentage of polymorphic bands (PPB) and polymorphism information content (PIC, according to Zhang et al. [58]). The Shannon information index (Ho), observed number of alleles per locus $(\mathrm{Na})$, and effective number of alleles per locus (Ne) were calculated using POPGENE (version 3.0, University of Alberta, Edmonton, AB, Canada) [59] under Hardy-Weinberg equilibrium (HWE). Nei's genetic diversity (Hj) was calculated using AFLP-SURV (version 1.0, ULB, Belgium) [60]. 


\subsubsection{Genetic Structure}

First, Nei's genetic distance (GD) of the population was calculated using AFLP-SURV v1.0 [60] with 10,000 bootstraps, and the results were used as inputs for computing the unweighted group method with arithmetic mean (UPGMA) tree using the CONSENSE module in PHYLIP (version 3.69, University of Washington, Seattle, WA, USA) [61]. Second, principal coordinates analysis (PCoA) for 100 individuals was conducted using the R packages "stats" [62] and "scatterplot3d" [63] to evaluate their spatial distribution pattern. Third, Bayesian model-based cluster analysis was performed to infer the number of clusters using the software STRUCTURE (version 2.3.4, Pritchard Lab, Stanford University, Stanford, CA, USA) [64] with correlated allele frequencies and an admixed model with a burn-in period of 50,000 and 200,000 MCMC (Monte carlo in markov chain) replicates after burn-in. The predefined cluster $(\mathrm{K})$ was $1-10$ with 10 runs per $\mathrm{K}$. The optimum $\mathrm{K}$ was decided by determining $\mathrm{L}(\mathrm{K})$ and $\triangle \mathrm{K}$ (the subtraction of two continuous $\mathrm{L}(\mathrm{K})$ values) using STRUCTURE HARVESTER (version 0.6.94, UCSC, Santa Cruz, CA, USA) [65]. Those values usually reached a plateau or increased slightly after reaching the "optimum $\mathrm{K}^{\text {". }}$

\subsubsection{Genetic Variation, Gene Flow and Genetic Barrier}

To further study the genetic differentiation (Fst) within and among populations, analysis of molecular variance (AMOVA) was conducted at different levels using the R package "vegan" [66]. The Shannon differentiation coefficient (G'st) was calculated according to the following formula: G'st $=($ Hsp - Hpop $) / H s p(H s p$, total Shannon information index; Hpop, average Shannon information index within the population). Gene flow $(\mathrm{Nm})$ was calculated as Fst $(\mathrm{Nm}=(1-\mathrm{Fst}) / 4 \mathrm{Fst})$. Moreover, a genetic barrier analysis was devised to suggest historical barriers to gene flow among or between collection sites using software BARRIER (version 2.2, Syracuse University, USA) [67] according to Monmonier's maximum difference algorithm, which treated geographical coordinates and genetic distance (GD) of each population as inputs.

\subsubsection{Correlation Analysis}

To examine the level of significance, the Pearson correlation between genetic diversity and environmental factors (annual mean temperature, annual precipitation, longitude, latitude and elevation) was estimated using the R package "ade4" (version 1.7.6, Aurélie Siberchicot) [68] with 1000 random permutations.

\section{Conclusions}

The results of this study demonstrate that environmental conditions in different habitats are major factors influencing the hereditary characteristic of species. The genetic diversity of F. ovina was relatively low. Population genetic diversity was decreased with increasing elevation, and it was also weakly related to temperature and precipitation but not correlated to latitude or longitude. Restricted gene flow was observed at different spatial scales, whereas genetic differentiation due to fragmentation was also detected between adjacent populations.

Acknowledgments: We thank all the participants for their contributions to this study. This work was supported by the National Key Basic Research Program of China (973 Program) (\#2014CB138705) and the Earmarked Fund for the Modern Agro-Industry Technology Research System (\#CARS-34). The funders had no role in study design, data collection and analysis, decision to publish, or preparation of the manuscript.

Author Contributions: Conceived and designed the experiment: Xiao Ma and Xinquan Zhang. Performed the experiment: Chenglin Zhang, Ming Sun and Wendan Wu. Analyzed the data: Chenglin Zhang, Xiaopeng Yang and Wenda Zhao and Xiao Ma. Searched the literature: Jianbo Zhang, Yan Fan, Yan Peng and Linkai Huang.

Conflicts of Interest: The authors declare no conflict of interest 


\section{References}

1. Morello, S.; Sede, S.M. Genetic admixture and lineage separation in a southern andean plant. AoB Plants 2016, 8, plw034. [CrossRef] [PubMed]

2. Hughes, C.E.; Atchison, G.W. The ubiquity of alpine plant radiations: From the andes to the hengduan mountains. New Phytol. 2015, 207, 275-282. [CrossRef] [PubMed]

3. Linder, H.P. Plant species radiations: Where, when, why? Philos. Trans. R. Soc. Lond. 2008, 363, 3097. [CrossRef] [PubMed]

4. Oostermeijer, J.G.B.; Luijten, S.H.; Nijs, J.C.M.D. Integrating demographic and genetic approaches in plant conservation. Biol. Conserv. 2003, 113, 389-398. [CrossRef]

5. Kremen, C.; Ricketts, T. Global perspectives on pollination disruptions. Conserv. Biol. 2000, 14, $1226-1228$. [CrossRef]

6. Saccheri, I.; Kuussaari, M.; Kankare, M.; Vikman, P.; Fortelius, W.; Hanski, I. Inbreeding and extinction in a butterfly metapopulation. Nature 1998, 392, 491-494. [CrossRef]

7. Bijlsma, R. The significance if genetic erosion in the process of extinction I. Genetic differentiation in Salvia pratensis L. And scabiosa columbaria in relation to population size. Heredity 1991, 66, 181-189.

8. Frankham, R. Conservation genetics. Ann. Rev. Genet. 1997, 78, 305.

9. Shaffer, H.B.; Gidiş, M.; Mccartney-Melstad, E.; Neal, K.M.; Oyamaguchi, H.M.; Tellez, M.; Toffelmier, E.M. Conservation genetics and genomics of amphibians and reptiles. Annu. Rev. Anim. Biosci. 2015, 3, 113. [CrossRef] [PubMed]

10. Bohrer, G.; Nathan, R.; Volis, S. Effects of long-distance dispersal for metapopulation survival and genetic structure at ecological time and spatial scales. J. Ecol. 2005, 93, 1029-1040. [CrossRef]

11. Reed, D.H.; Lowe, E.H.; Briscoe, D.A.; Frankham, R. Inbreeding and extinction: Effects of rate of inbreeding. Conserv. Genet. 2003, 4, 405-410. [CrossRef]

12. Gu, X.Y.; Guo, Z.H.; Ma, X.; Bai, S.Q.; Zhang, X.Q.; Zhang, C.B.; Chen, S.Y.; Peng, Y.; Yan, Y.H.; Huang, L.K. Population genetic variability and structure of Elymus breviaristatus (poaceae: Triticeae) endemic to Qinghai-Tibetan plateau inferred from ssr markers. Biochem. Syst. Ecol. 2015, 58, 247-256. [CrossRef]

13. Cota, L.G.; Vieira, F.A.; Melo Júnior, A.F.; Brandão, M.M.; Santana, K.N.; Guedes, M.L.; Oliveira, D.A. Genetic diversity of Annona crassiflora (annonaceae) in northern minas gerais state. Genet. Mol. Res. GMR 2011, 10, 2172-2180. [CrossRef] [PubMed]

14. Carter, T.E., Jr.; Hymowitz, T.; Nelson, R.L. Biogeography, Local Adaptation, Vavilov, and Genetic Diversity in Soybean; Biol. Resour. Migr; Springer: Berlin, Germany, 2004; pp. 47-59.

15. Juan, A.; Crespo, M.B.; Cowan, R.S.; Lexer, C.; Fay, M.F. Patterns of variability and gene flow in Medicago citrina, an endangered endemic of islands in the western mediterranean, as revealed by amplified fragment length polymorphism (aflp). Mol. Ecol. 2004, 13, 2679-2690. [CrossRef] [PubMed]

16. Young, A.; Boyle, T.; Brown, T. The population genetic consequences of habitat fragmentation for plants. Trends Ecol. Evol. 1996, 11, 413. [CrossRef]

17. Edelaar, P.; Alonso, D.; Lagerveld, S.; Senar, J.C.; Björklund, M. Population differentiation and restricted gene flow in spanish crossbills: Not isolation-by-distance but isolation-by-ecology. J. Evol. Biol. 2012, 25, 417. [CrossRef] [PubMed]

18. Müller, C.M.; Schulz, B.; Lauterbach, D.; Ristow, M.; Wissemann, V.; Gemeinholzer, B. Geropogon hybridus (L.) Sch.Bip. (Asteraceae) exhibits micro-geographic genetic divergence at ecological range limits along a steep precipitation gradient. Plant Syst. Evol. 2016, 303, 1-14. [CrossRef]

19. Schuster, W.S.; Alles, D.L.; Mitton, J.B. Gene flow in limber pine: Evidence from pollination phenology and genetic differentiation along an elevational transect. Am. J. Bot. 1989, 76, 1395-1403. [CrossRef]

20. Hewitt, G. The genetic legacy of the quaternary ice ages. Nature 2000, 405, 907-913. [CrossRef] [PubMed]

21. Hewitt, G.M. Genetic consequences of climatic oscillations in the quaternary. Philos. Trans. R. Soc. Lond. 2004, 359, 183-195. [CrossRef] [PubMed]

22. Staneik, D. The genus Festuca (Poaceae: Loliinae) in venezuela. Nord. J. Bot. 2003, 23, 191-205. [CrossRef]

23. Harberd, D.J. Some observations on natural clones in Festuca ovina. New Phytol. 1962, 61, 85-100. [CrossRef]

24. Weibull, P.; Ghatnekar, L.; Bengtsson, B.O. Genetic variation in commercial varieties and natural populations of sheep's fescue, Festuca ovina L. Plant Breed. 1991, 107, 203-209. [CrossRef] 
25. Wilkinson, M.J.; Stace, C.A. A new taxonomic treatment of the Festuca ovina L. Aggregate (poaceae) in the british isles. Bot. J. Linn. Soc. 2010, 106, 347-397. [CrossRef]

26. Mirhaji, M.; Sanadgol, A.; Jafari, A.A. Evaluation of 16 accessions of Festuca ovina L. In the nursery of homand-abesard rangeland research station. Desalination 2013, 148, 25-29.

27. Liu, C.E.; Peng, X.U.; Sha-Zhou, A.N. Study on the growing rhymes of plants of grassland in northern slope of tianshan mountain. Chin. J. Grass. 2006, 28, 18-21.

28. Wang, J. Study on grassland vegetation and its utilization of mid-low belt of north slopes of tianshan mountains. Anim. Husb. Feed Sci. 2009, 5, 133-142.

29. Stroeven, A.P.; Hättestrand, C.; Heyman, J.; Kleman, J.; Morén, B.M. Glacial geomorphology of the tian shan. J. Maps 2013, 9, 505-512. [CrossRef]

30. Li, Y.; Liu, G.; Chen, Y.; Li, Y.; Harbor, J.; Stroeven, A.P.; Caffee, M.; Zhang, M.; Li, C.; Cui, Z. Timing and extent of quaternary glaciations in the tianger range, eastern tian shan, china, investigated using 10 be surface exposure dating. Quat. Sci. Rev. 2014, 98, 7-23. [CrossRef]

31. Kong, P.; Fink, D.; Na, C.; Huang, F. Late quaternary glaciation of the tianshan, central asia, using cosmogenic be surface exposure dating. Quat. Res. 2009, 72, 229-233. [CrossRef]

32. Su, Z.; Zhang, M. Evolutionary response to quaternary climate aridification and oscillations in north-western china revealed by chloroplast phylogeography of the desert shrub Nitraria sphaerocarpa (Nitrariaceae). Biol. J. Linn. Soc. 2013, 109, 757-770. [CrossRef]

33. Meng, H.H.; Gao, X.Y.; Huang, J.F.; Zhang, M.L. Plant phylogeography in arid northwest China: Retrospectives and perspectives. J. Syst. Evol. 2015, 53, 33-46. [CrossRef]

34. Hu, T. Assessing genetic diversity of perennial ryegrass (Lolium perenne L.) from four continents by inter-simple sequence repeat (ISSR) markers. Afr. J. Biotechnol. 2011, 10, 19365-19374.

35. Keyghobadi, N.; Roland, J.; Matter, S.F.; Strobeck, C. Among- and within-patch components of genetic diversity respond at different rates to habitat fragmentation: An empirical demonstration. R. Soc. Proceed. B Biol. Sci. 2005, 272, 553-560. [CrossRef] [PubMed]

36. Nations, F.A.O.O. The state of the world's plant genetic resources for food and agriculture. J. Plant Genet. Resour. 2011, 12, 3-8.

37. Mueller, U.G.; Wolfenbarger, L.L. Aflp genotyping and fingerprinting. Trends Ecol. Evol. 1999, 14, 389. [CrossRef]

38. Durrant, W.E.; Rowland, O.; Piedras, P.; Hammondkosack, K.E.; Jones, J.D.G. Cdna-aflp reveals a striking overlap in race-specific resistance and wound response gene expression profiles. Plant Cell 2000, 12, 963. [CrossRef] [PubMed]

39. Luo, R.; Larget, B. Modeling substitution and indel processes for aflp marker evolution and phylogenetic inference. Ann. Appl. Stat. 2009, 3, 222-248. [CrossRef]

40. Breyne, P.; Rombaut, D.; Van, G.A.; Van, M.M.; Gerats, T. Aflp analysis of genetic diversity within and between arabidopsis thaliana ecotypes. Mol. Gener. Genet. MGG 1999, 261, 627. [CrossRef]

41. Gu, F. Genetic structure in population of reaumuria soongorica in the desert of fukang, xinjiang and its relationship with ecological factors. Acta Bot. Sin. 2003, 45, 787-794.

42. Feng, L.I.; Xiong, Z.; Fengmin, L.I.; Zhu, Y. Genetic diversity and divergence between populations of Hemerocallis lilioasphodelus L. from henan and hunan province. Wuhan Univ. J. 1999, 45, 449-851.

43. Sorkheh, K.; Masaeli, M.; Chaleshtori, M.H.; Adugna, A.; Ercisli, S. Aflp-based analysis of genetic diversity, population structure, and relationships with agronomic traits in rice germplasm from north region of iran and world core germplasm set. Biochem. Genet. 2016, 54, 1-17. [CrossRef] [PubMed]

44. Majidi, M.M.; Mirlohi, A.F.; Sayedtabatabaei, B.E. Aflp analyses of genetic variation in iranian fescue accessions. Pak. J. Biol. Sci. 2006, 9, 1869-1876.

45. Tehrani, M.S.; Díaz-Pérez, A. Genetic diversity and structure among iranian tall fescue populations based on genomic-ssr and est-ssr marker analysis. Plant Syst. Evol. 2009, 282, 57-70. [CrossRef]

46. Rao, V.R.; Hodgkin, T. Genetic diversity and conservation and utilization of plant genetic resources. Plant Cell Tissue Organ Cult. 2002, 68, 1-19.

47. Fjellheim, S.; Grieg, Z.; Rognli, O.A. Aflp-marker analyses of genetic structure in nordic meadow fescue (Festuca pratensis huds.) - Tracing the origin of norwegian cultivars and local populations. Dev. Plant Breed. 2004, 11, 303-308. 
48. Hayes, B.J.; Cogan, N.O.I.; Pembleton, L.W.; Goddard, M.E.; Wang, J.; Spangenberg, G.C.; Forster, J.W. Prospects for genomic selection in forage plant species. Plant Breed. 2013, 132, 133-143. [CrossRef]

49. Stephan, W. Principles of population genetics. Q. Rev. Biol. 2007, 82, 416. [CrossRef]

50. Thomson, J.D. Skewed flowering distributions and pollinator attraction. Ecology 1980, 61, 572-579. [CrossRef]

51. Bingham, R.A.; Orthner, A.R. Efficient pollination of alpine plants. Nature 1998, 391, 238-239. [CrossRef]

52. Han, X.Y.; Yang, Q.; Yao, J.Q. Spatiotemporal distribution characteristics of precipitation in tianshan mountain of xinjiang during the last 51 years. Res. Soil Water Conserv. 2013, 20,139-144.

53. Zhang, Q.; Singh, V.P.; Li, J.; Jiang, F.; Bai, Y. Spatio-temporal variations of precipitation extremes in xinjiang, china. J. Hydrol. 2012, 434-435, 7-18. [CrossRef]

54. Roughgarden, J.; Bergman, A.; Shafir, S.; Taylor, C. Adaptive Computation in Ecology and Evolution: A Guide for Future Research; Adaptive Individuals in Evolving Populations: Boston, MA, USA, 1996; pp. 25-30.

55. Ye, M.; Hou, B.; Luo, J.; Yan, W.; Liu, W.; Ding, X. Genetic diversity and conservation of the endangered herb dendrobium moniliforme based on amplified fragment length polymorphism markers. Sci. Horticult. 2015, 189, 51-58. [CrossRef]

56. Gandon, S.; Nuismer, S.L. Interactions between genetic drift, gene flow, and selection mosaics drive parasite local adaptation. Am. Nat. 2009, 173, 212-224. [CrossRef] [PubMed]

57. Ahloowalia, B.S. A root tip squash technique for screening chromosome number in Lolium. Euphytica 1965, 14, 170-172. [CrossRef]

58. Zhang, L.; Jeon, Y.J.; Kang, S.Y.; Lee, G.J. Genetic diversity of natural and artificial populations of model grass brachypodium species evaluated by aflp markers. Horticult. Environ. Biotechnol. 2012, 53, 143-150. [CrossRef]

59. Juan, A.; Fay, M.F.; Pastor, J.; Juan, R.; Fernández, I.; Crespo, M.B. Genetic structure and phylogeography in Juniperus oxycedrus subsp. Macrocarpa around the mediterranean and atlantic coasts of the iberian peninsula, based on aflp and plastid markers. Eur. J. For. Res. 2012, 131, 845-856. [CrossRef]

60. Dzialuk, A.; Mazur, M.; Boratyńska, K.; Montserrat, J.M.; Romo, A.; Boratyński, A. Population genetic structure of Juniperus phoenicea (cupressaceae) in the western mediterranean basin: Gradient of diversity on a broad geographical scale. Ann. For. Sci. 2011, 68, 1341-1350. [CrossRef]

61. Peters, M.D.; Xiang, Q.Y.; Thomas, D.T.; Stucky, J.; Whiteman, N.K. Genetic analyses of the federally endangered Echinacea laevigata using amplified fragment length polymorphisms (aflp)-Inferences in population genetic structure and mating system. Conserv. Genet. 2009, 10, 1-14. [CrossRef]

62. Coreteam, R.D. R: A language and environment for statistical computing. Computing 2015, 14, $12-21$.

63. Ligges, U.; Martin, M. An r package for visualizing multivariate data. J. Stat. Softw. 2003, 08, 11. [CrossRef]

64. Chen, Y.Y.; Li, L.; Wei, L.; Li, Z.Z. Genetic diversity and population structure of the endangered alpine quillwort isoetes hypsophila hand.-mazz. revealed by aflp markers. Plant Syst. Evol. 2010, 290, 127-139. [CrossRef]

65. Falush, D.; Stephens, M.; Pritchard, J.K. Inference of population structure using multilocus genotype data: Dominant markers and null alleles. Mol. Ecol. Resour. 2007, 7, 574-578. [CrossRef] [PubMed]

66. Last, L.; Widmer, F.; Fjellstad, W.; Stoyanova, S.; Kölliker, R. Genetic diversity of natural orchardgrass (Dactylis glomerata L.) populations in three regions in europe. BMC Genet. 2013, 14, 102. [CrossRef] [PubMed]

67. Sui, X.Q.; Wang, K.; Zheng, S.H.; Li, L.; An, S.Z. Effects of landscape fragmentation on genetic diversity of stipa Krylovii roshev (Stipa L.) in agro-pastoral ecotone in northern china. Afr. J. Biotechnol. 2009, 8, 155-160.

68. Thioulouse, J.; Dray, S. Interactive multivariate data analysis in R with the ade 4 and ade4tkgui packages. J. Stat. Softw. 2007, 22, 1-14. [CrossRef]

Sample Availability: Samples of the compounds are available from the authors. 